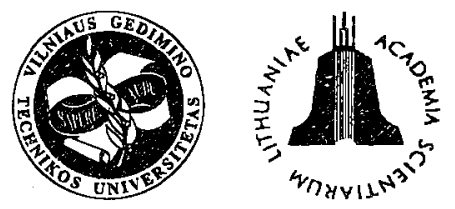

ISSN 1648-4142 TRANSPORT

http:/www.vtu.lt/english/editions

\title{
THE INTELLIGENT SYSTEMS OF AUTOMOTIVE ACTIVE SAFETY
}

\author{
Valentin Ivanov ${ }^{1}$, Vladimir Boutylin ${ }^{2}$ \\ ${ }^{1}$ Belarusian National Technical University, 65 F. Skaryny al., 220013 Minsk, Belarus \\ ${ }^{2}$ National Academy of Sciences of Belarus, 12 Academicheskaja, 220072 Minsk, Belarus \\ Received 200205 28; accepted 20020910
}

\begin{abstract}
The subject of research is the idea of creation automobile systems of active safety basing on predictable use of potential possibilities of a wheel coupling with a road.

Together with the generally accepted dependencies between the tire grip $\mu$ wheel slip, $s$, it is expedient to use potential $\mu$-s-curves which can be deduced, having applied some postulates of the friction theory to the process of wheel-road interaction. In the work the basic dependencies for qualitative estimation of the specified components are given.

As the result the concept of an intelligent system of active safety which is based on the control philosophy of predictable use of a tire grip is offered.
\end{abstract}

Keywords: safety, tire grip, slip, intelligent system.

\section{Introduction}

Active safety as the complex factor reflecting dynamic parameters, reliability, ergonomics and other basic attributes of the automobile to a great extent defines the competitiveness of a modern vehicle. The system of active safety (SAS) is an independent component of the automobile which incorporates data-control channels and devices, basic units and assemblies of the automobile with the aim of avoidance or minimization of possible consequences of a critical road-operational situation.

Herewith, the control processes are featured by: foresee-ability; self-training and self-configurability that are attributes of an intelligent object (Fig1.).

The creation of an active safety intelligent system is carried out in three major directions:

- the development of adaptive control and forecast algorithms,

- the definition of necessary and sufficient information space in the environment "automobile - wheel road" for timely recognition of a critical situation or a tendency of approach to it,

- the formation of a flexible constructive structure.

The given aspects are subjects of the paper.

\section{Wheel as a Control Object of SAS}

\subsection{The Power and Force Balance of the Braking Wheel \\ The modern systems of active safety (for example,}

'E-mail: valgeoiva@netscape.net

${ }^{2}$ E-mail: bvg@tut.by

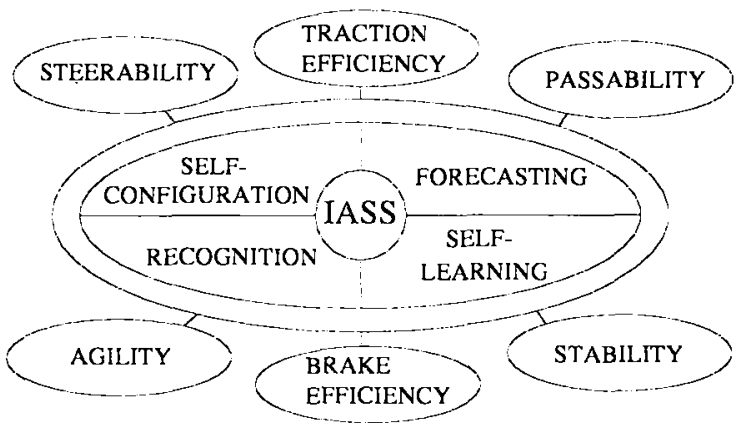

Fig 1. Goals of a system of active safety

ABS, TCS, VDC) are capable of ensuring an adequate reaction in a possible critical situation only within the limited regulation area.

The basic reason is the use of algorithms, the work ideology of which is based on threshold logic of the executive devices management - brake gear, power unit and suspension. The parameters of work quality of a wheel and automobile thus are not taken into account or remain secondary.

The analytical research series which have been carried out allow us to offer another approach in regulation philosophy, namely, management on the basis of energydistribution regulation. Actually, an intelligent system of active safety (ISAS) should be able to recognize and to work at two energy levels simultaneously. The micro-level is an area of interaction of a wheel with a road, macro-level - processes describing behavior of the automobile.

For a choice of necessary and sufficient working parameters ISAS we shall consider a wheel at a micro-level (Fig 2). 


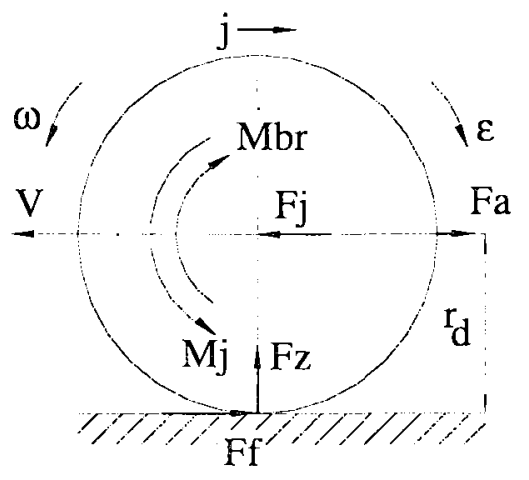

Fig 2. Wheel forces and moments at braking

The forces action in a road-wheel-automobile system is usually considered relatively to the wheel rotation center and in this case a force balance equation is known:

$$
m \frac{d V}{d t}=-\frac{M_{b r}}{r_{d}}-\frac{M_{j}}{r_{d}} \leq \mu F_{z}
$$

Evidently, the classic equation (1) that can be found practically in every textbook on the automobile theory does not allow to take account of interrelationship between forces and kinematic parameters of a wheel motion. It is expedient to use energy equations (2) - (8) for a fuller description of processes:

$$
\begin{aligned}
& E=\frac{m V^{2}}{2}+\frac{J \omega^{2}}{2}, \\
& \frac{d E}{d t}=N=m V \frac{d V}{d t}+J \omega \frac{d \omega}{d t}, \\
& V_{s}=V-\omega \cdot r_{d}, \\
& F_{\mu}=\mu(V) F_{z}(V), \\
& m V \frac{d V}{d t}+J \omega \frac{d \omega}{d t}=M_{b r} \omega+F_{\mu} V_{s}, \\
& s=\frac{V_{s}}{V}, \\
& m \frac{d V}{d t}=F_{\mu}+(1-s)\left(\frac{M_{b r}}{r_{d}}-\frac{J}{r_{d}} \frac{d \omega}{d t}-F_{\mu}\right) .
\end{aligned}
$$

At boundary conditions the expression (8) will become the equation (1) at $s=0$, and expression (9) at $s=1$ :

$$
m \frac{d V}{d t}=F_{\mu} \quad \text { or } \quad \frac{d V}{d t}=\mu g .
$$

The equations disclose that with the increase of a slip coefficient $s$, the power flow on a wheel redistributes from wheel-brake gear to wheel-road contact. As a result, the efficiency of an usual automatic control reduces be- cause on the one hand a tracing of reasons and drift direction of wheel coupling coefficient becomes more difficult and on the other hand, a necessity for regulation arises not only by the time (equation (1)), but also by a sliding (equation (8)).

\subsection{Potential Forces in a Wheel-Road-Contact}

Next, the most important remark is connected with the notion of a wheel-road coupling coefficient. Actually, the known generations of active safety systems are control systems of wheel slipping. In this case the dependence of tangential force (coupling), $\mu_{X}$, and lateral wheel force, $\mu_{Y}$, from slip coefficient, $s$, is considered as sufficient management characteristics (Fig 3).

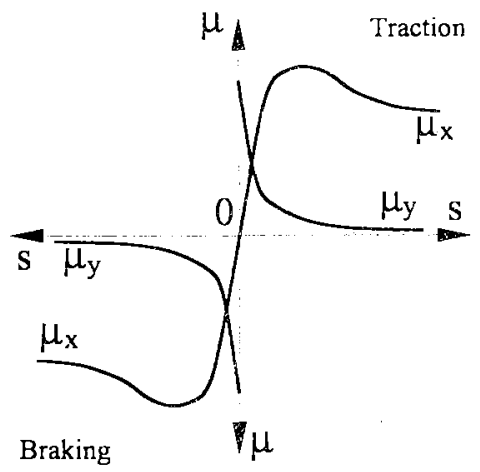

Fig 3. Classical $\mu$-s-curves

The given approach is known from the classical theory of automobile in spite of the fact that the authentic analytical description of $\mu$-s-dependence is absent and the accepted kind of $\mu$-s-curves is pretty moot for the field of small sliding. On the strength of the experimental research results of the given characteristics in Technical University Karlsruhe for test bench conditions and DaimlerChrysler in the real conditions, the definition of $\mu$ $s$-dependencies begins at conditions of an equaling linear speed of the automobile near $3 \mathrm{~km} / \mathrm{h}$. In this area the certain fluctuations of a slip value are observed $[1,2]$. However at final processing of tests results this factor is neglected and the dependence of the circumferential force coefficient from slip relation is extrapolated up to 0 practically linearly.

It is also necessary to note that the common kind of $\mu$ $\mathrm{s}$-curves theoretically will not fully match the basic rules of tribology; in this connection the specific revision of some rules of the wheel-road interaction theory is necessary.

As far as the part of a wheel grip force is spent on frictional bonds destruction, it points its potential character. For the creation of a sliding contact between a moving wheel and a support surface the forces in contact should have potential grip. Therefore, at the initial moment the slip coefficient and consequently also the grip force should 
have some values distinct from 0 , otherwise it will not correspond to the potential character of forces within contact. Thus, it is possible to speak about the certain potential barrier (Fig 4).

$$
\mathrm{F} \mu
$$

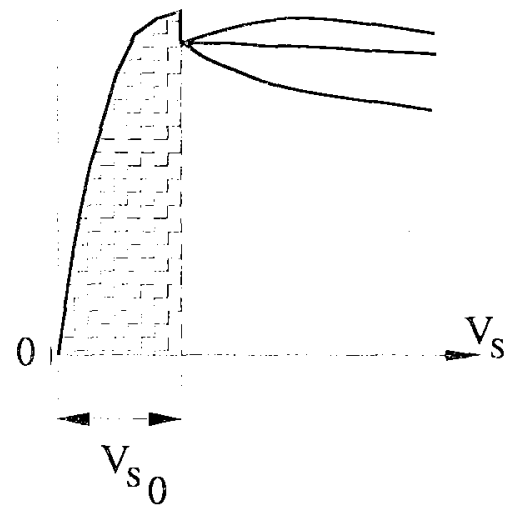

Fig 4. Potential barrier of the tire grip force

Taking into account a physical meaning of grip coefficient the potential force in contact of a wheel to a road is formed by five basic components:

$$
F \mu^{P}=f\left(F_{z}, V_{s}, F \mu_{x}^{a d h}, F \mu_{x}^{d e f}, F \mu_{Y}\right) .
$$

Depending on the contribution factor that is dominant in a given situation, the potential dependence $F \mu^{P}(s)$ will be described by various curves (Fig 5). The curve " $c$ " is characteristic for a curvilinear motion of the automobile, "b" - for a motion on roads with low coupling (deformation component prevails), "a" - for a motion on roads with good grip properties (adhesion component prevails). Herewith, the initial wheel slip velocity $V_{s}$ defines a starting curve position on axis $\mu$, and a change of vertical reaction $F_{z}$ determines a curve drift.

As intelligent system of active safety has not to be only capable to extricate the automobile from de facto ex-

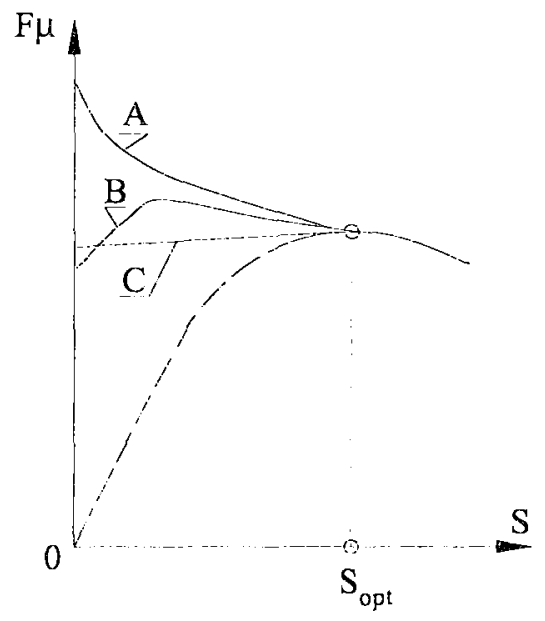

Fig 5. Potential $F \mu$-s-curves isting critical situation, but, first of all, to control automobile with forecasting, potential dependencies $F \mu((s)$ should be used for describing working wheel characteristics.

Tracing the change $d F \mu / d s$, ISAS predicts the approach tendency of a wheel to unstable area $F \mu$-s-curve $\left(s_{\text {opt }}\right)$ and carries out preventive regulation of circumferential and sidelong forces.

Here for concrete technical implementation the methods of pre-extreme regulation may be applied $[3,4]$.

\subsection{Some Aspects of Slip Evaluation}

From a qualitative rating of wheel-road-interaction we shall proceed to a quantitative rating.

For a quantitative rating by analogy with coefficient of sidelong withdrawal $k_{\alpha}$, we shall constitute force coefficient concept of tangential slip $k_{X}$ [5]. The specified coefficients functionally depend on a type of tires, road carpet, other constructive and operational factors. Coefficients $k \alpha$ and $k_{X}$ allow to connect force and kinematic components of wheel-road-interaction (Table).

\section{Interaction between Road Loading and Wheel Slip}

One more important aspect which should be illuminated in a theoretical part takes into account a loading change on a wheel during management.

The wheel - road contact is formed by two independent variables, (Fig 6). Because a normal loading is composed of cyclic and random processes it is on the whole an independent variable. It is formed by the gravity and the spring-mass system of an automobile, having spacetemporal dependence at the same time. One more independent variable is braking torque. Although these variables define boundary conditions which are continuously drifted under the influence of road roughness they are not taken into account by modern systems. As a rule known algorithms take into account only redistribution of a vertical loading under the influence of automobile inertia forces.

As the regulators of braking forces in some degree compensate the influence only of macro-roughness estimating of the combined influence both macro and micro-

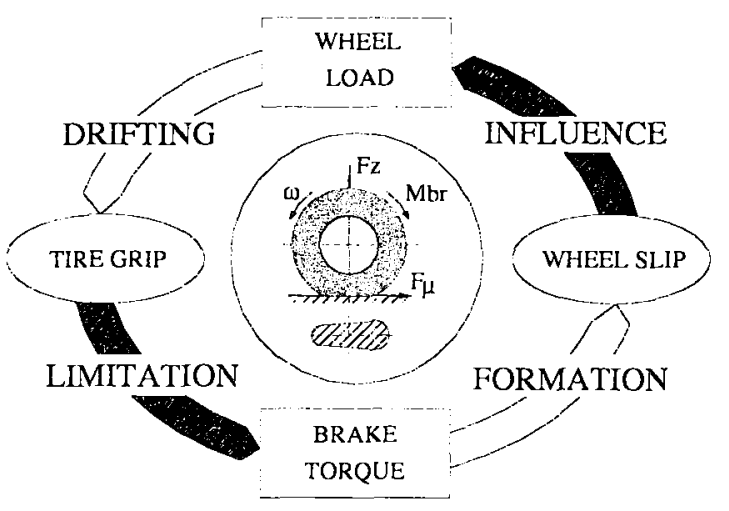

Fig 6. Formation of a Wheel-Road-Contact 


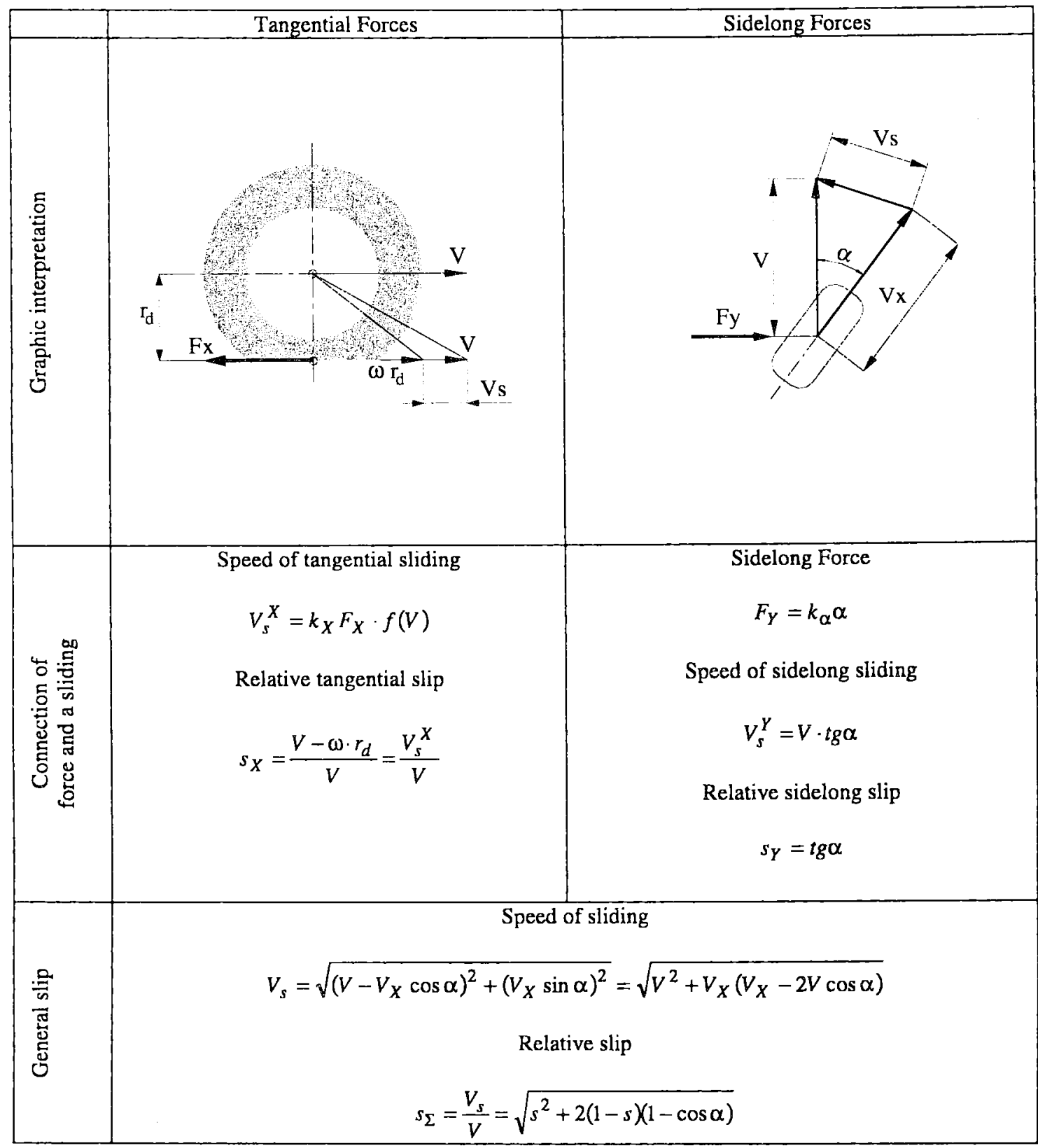

roughness becomes one of ISAS tasks. Namely it is the definition of slip drift parameters in a lateral and longitudinal directions for the current spectra of road loading.

Here, as a logical alternative the following approach may be proposed. As the first approximation it is enough to limit the amplitude value of the strength of the executive devices opportunities. Approaching to ISAS work frequency that is limited by the operating speed of the executive devices, the limitation is abolished. Further correction through averaging is made. Besides, whereas the spectra of practically all road carpet types are known, on ergodic properties of a road the IASS has to foresee the reaction of spring-mass system of automobile already for the first phase of regulation.

Prospects for systems of Steer-by-Wire and for management systems of active suspension not only for the promotion of assurance of smooth running and convenience increase, but also for the preservation of automobile stability and braking efficiency are opened.

\section{Conception of an Intelligent System of Active Safety}

The overwhelming majority of modern active safety systems have a daisy-chain information structure on a principle "1 object -1 sensor -1 control parameter". Modern microelectronic and mechatronic components allow to embody more flexible organization of active safety systems with realization of parallel structure of information channels $[6,7]$.

Being based on the above-stated IASS control principles, the information from sensors is processed so that to receive not only current parameter value, but its tempo- 
ral dependence. It allows to trace the tendencies of approaching of management object to critical area of motion. Depending on a rating of the current management situation, ISAS places priorities for information channels, that is, only one basic parameter of regulation is selected and others carry out control and correction functions.

Generally the number of channels is only limited by economic expediency (Fig 7).

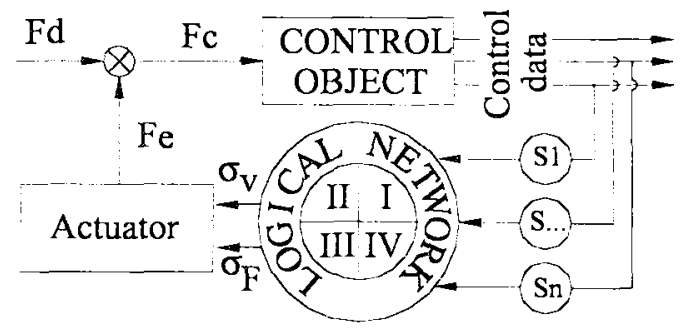

Fig 7. SAS with Parallel Informational Chanells

The analysis of the above equations discloses that a minimum of three parallel channels can be realized in the system. Along a direct channel the information is sent from the wheel-road contact force sensor about value $F \mu$ . For two indirect channels sensor of automobile deceleration $j$ (for example longitudinal and lateral accelerometers and gyroscope) and braking torque $M_{b r}$ sensor are required. Besides, speed sensors of wheel and automobile which obtain the information about $s$ and $d s$ are the base for all channels.

It will be expedient to unite information channels by network (for example, CAN or optical glass-fibre). In case that some element is failed, the serviceability of system is supported via resources redistribution or reconfiguring. One of the channels presents a priority channel for a concrete critical situation and others can supplement or correct the information. For example, during emergency braking or acceleration of automobile on a sloped road the terrestrial gravitation field imposes disturbance on process of regulation; therefore here IASS chooses channel $j$ as master channel. During service braking of an automobile using an engine the information about the torque $M_{b r}$ carries out correction function and at movement on ice, where the values $s$ and ds are the most important, all channels correct the information from speed sensors.

For the account of road properties, ISAS has to have sensor set connected to suspension (Fig 8). So, on the information from non-dampened displacement sensor it is possible to define the boundary frequency of ISAS for suspension abilities, the reaction sensor gives the torque from circumferential forces after deduction of inertial moment of wheel. Accelerometer sensor is capable of giving the information for the definition of drift character by the system.

It is possible to say that ISAS has all attributes of smart-system (intelligent system) owing to the submitted philosophy of regulation and structure of sensor and executive parts. As a result the intelligent active safety sys-

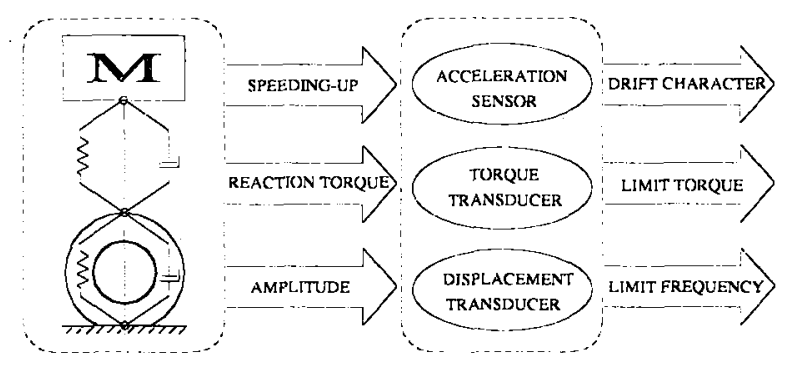

Fig 8. Account of Road Conditions in ISAS

tem is very closely integrated with the driver and current road situation.

As a result of the carried out research on the creation of ISAS a structure of concept-system is formed by the authors (Fig 9).

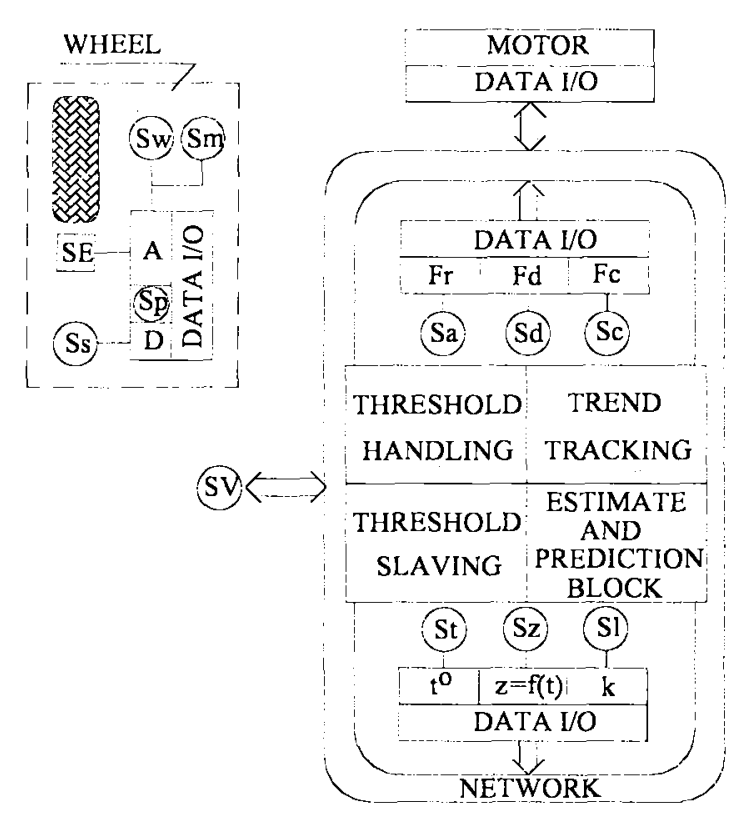

Fig 9. Concept System

Intelligent active safety system has:

- Powerful informative-calculated analytical part in network version (CAN or optical-fiber) for effective management;

- Fast and dosated action of the executive devices;

- Ability to define a priority of commands and status of devices in a network for a particular control situation and also to redistribute resources at failure or channels overload of information exchange and managing elements;

- Ability to retarget elements of a circuit "information-computing-management" depending on the stored experience of work with a concrete object.

\section{Conclusions}

The intelligent system of active safety is optimally connected with the driver and road-operational situation. 
The ideology of intelligent systems of active safety is being formed. However it is already possible to accentuate the following attributes of similar devices:

Into the basis of philosophy of regulation ISAS the potential characteristics of forces in contact of a wheel with a road have been laid, which allow more adequately to connect wheel grip with its slip - the most important information for active safety of the automobile.

The philosophy of regulation has to base on the methods of pre-extreme management on $F \mu$-s-curves which ensure keeping the properties of automobile stability and sufficient using degree of braking or traction efficiency.

For ensuring the described control philosophy the sensor part should have a parallel structure with several independent information channels, in result the system gets information flexibility and its reliability is improved

\section{Definitions, Acronyms, Abbreviations}

ABS: Antilock Braking System

ISAS: Intelligent System of Active Safety

TCS: Traction Control System

VDC: Vehicle Dynamics Control System

S: Sensor

Sa: Acceleration sensor for brake pedal

Sc: Steering sensor

Sd: Sensor of brake pedal displacement

SE: Servo-element

Sl: Roll sensor

Sm: Brake moment sensor

Sp: Pressure sensor

Ss: Suspension sensor

St: Temperature sensor

SV: Vehicle speed sensor

Sw: Wear sensor

Sz: Gyroscope

A: Acceleration of the brake pedal

D: Displacement of the brake pedal

E: Energy of wheel movement

Fa: Aerodynamic force

Fc: Control effort

Fd: Driver effort at the brake pedal

Fe: Correction effort

Ff: Rolling resistance force

Fj: Force of the vehicle inertia

Fr: Reaction force at the brake pedal

Fz: Wheel load, road loading

$\Phi \mu$ : Force in the wheel-road-contact

$\Phi \mu^{P}$ : Potential force in the wheel-road-contact

$\Phi \mu_{\mathrm{x}}$ : Longitudinal force in the wheel-road-contact

$\boldsymbol{\Phi} \mu_{\mathrm{x}}{ }^{\mathrm{ADH}}$ : Adhesion component of force in the wheel-roadcontact

$\Phi \mu_{\mathbf{X}}{ }^{\mathrm{DEF}}$ : Deformation component of force in the wheel-

road-contact

$\Phi \mu_{\mathbf{Y}}$ : Sidelong force in the wheel-road-contact

g: Gravitational acceleration

j: Braking deceleration of the automobile
$\mathbf{J}$ : inertia of a wheel

k: Roll of car

$\mathbf{k}_{\mathbf{x}}$ : Force coefficient of tangential slip

$\mathbf{k}_{\mathbf{k}}$ : Coefficient of a sidelong withdrawal

m: Given on a wheel weight of the automobile

Mbr: Braking moment

Mj: Moment of wheel inertia

$\mathbf{N}$ : Power of the wheel movement

$\mathbf{r}_{\mathbf{d}}$ : Dynamic radius of a wheel

s: Wheel slip

$\mathbf{s}_{\mathbf{Y}}$ : Sidelong slip

$\mathbf{s}_{0}$ : Relative general slip

$\mathbf{s}_{\mathrm{OPT}}$ : Optimum of wheel slip

t: Temperature

V: Linear speed of the automobile

$\mathbf{V}_{\mathbf{s}}$ : Speed of sliding

$\mathbf{V}_{\mathbf{S}} \mathbf{x}$ : Speed of tangential sliding

$\mathbf{V}_{\mathbf{S}} \mathbf{Y}_{\mathbf{S}}$ : Speed of sidelong sliding

$\mathbf{V}_{\mathbf{S}} \mathbf{o}$ : Barrier speed of sliding

z: Gyro moment

$\alpha$ : Sidelong breakaway

$\mu$ : Tire grip, wheel cohesion

$\mu_{\mathrm{x}}:$ Longitudinal tire grip

$\mu_{\mathrm{Y}}$ : Sidelong tire grip

$\sigma_{\mathbf{F}}$ : Vector signal of control effort

$\sigma_{\mathrm{v}}$ : Dynamic signal of control effort

$\omega$ : Angular velocity of a wheel

$\varepsilon$ : Angular acceleration of a wheel

\section{References}

1. Gnadler R., Unrau H.-J., Fischlein H., Frey M. Ermittlung von ǵ-Schlupf-Kurven an Pkw-Reifen. FAT-Schriftenreihe, No 119, Frankfurt am Main: FAT, 1995. 170 p.

2. Leister G., Runtsch G., Widmayer H. Ermittlung objektiver Reifeneigenschaften im Entwicklungsprozess mit einem Reifenmessbus. Automobiltechnische Zeitschrift, Vol 101, No 5. Wiesbaden: Vieweg Verlag, 1990, p 318-324.

3. Leschinsky A. I., Boutylin V. G., Ivanov V. G. The beforethe-extreme method of vehicle braking automatic control. In: Proc. of the National Academy of Sciences of Belarus, Physico-Technical Series, No 1. Minsk: NANB, 2000, p. 45-49 (in Russian).

4. Ivanov V., Boutylin V., Liashchinski A. Structural Synthesizing of Intellectual Systems of Automobile Active Safety. Detroit: SAE, Paper 2000-01-1637. 9 p.

5. Ivanov V., Boutylin V., Lepeshko J. Control philosophy for intelligent active safety systems. In: ISATA 2000, paper 00CE012. Epsom: ISATA, 2000, p 293-298.

6. Ivanov V., Boutylin V., Lepeshko J. A Control of the Wheel as a Partition of Mechatronic System in the Potential Field of Cohesion. Mechatronic, No 4. Moscow: Novye technologii, 2000, p 14-18 (in Russian).

7. Boutylin V., Ivanov V. Mechatronic systems of active safety of automobiles. In: Proc. of First International Conference on Mechatronics and Robotics "MiR' 2000". Sanct-Petersburg: NPO "Onega", 2000, p 58-64 (in Russian). 